LA-UR- $98=2646$

Approved for public release; distribution is unlimited.

Title:

MECHANISMS RESPONSIBLE FOR TEXTURE DEVELOPMENT

IN A 5182 ALUMINUM ALLOY DEFORMED AT ELEVATED

TEMPERATURE

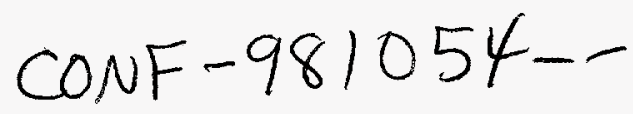

Author(s):

M. G. STOUT

S. R. CHEN

U. F. KOCKS

A. J. SCHWARTZ

S. R. MACEWEN

A. J. BEAUDOIN

Submitted to:

TMS FALL MEETING

ROSEMENT, IL

$10 / 12-15 / 98$

MASTER

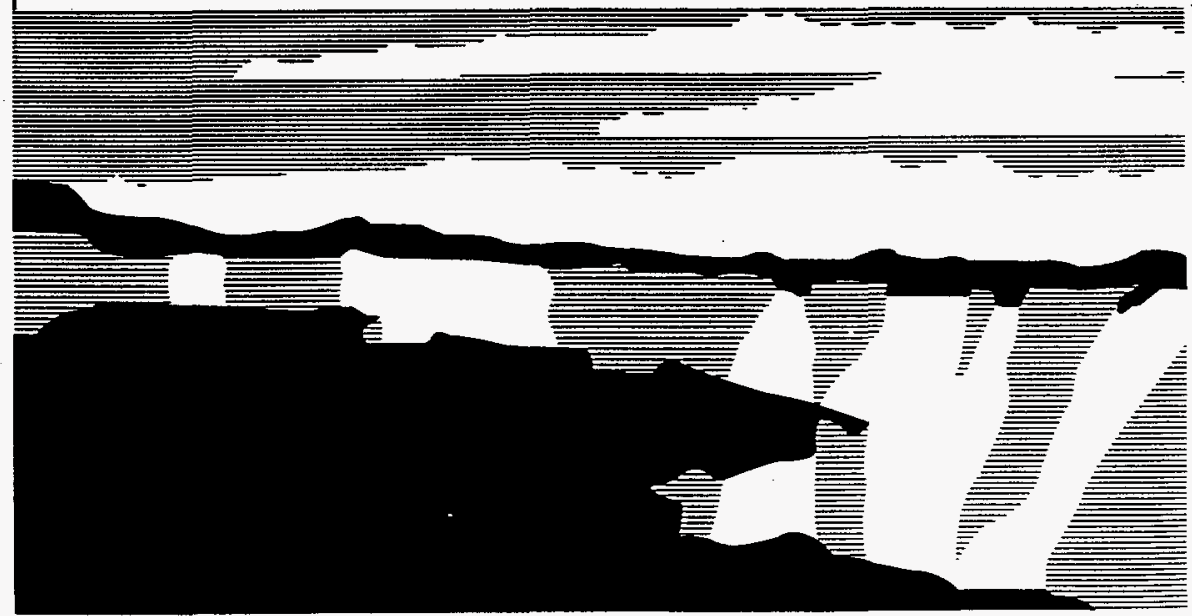

Los Alamos National Laboratory, an aftimative action/equal opportunity employer, is operated by the University of Califomia for the U.S. Department of Energy under contract W-7405-ENG-36. By acceptance of this article, the publisher recognizes that the U.S. Govemment retains a nonexclusive, royalty-free license to publish or reproduce the published form of this contribution, or to allow others to do so, for U.S. Govermment purposes. Los Alamos National Laboratory requests that the publisher identify this article as work performed under the auspices of the U.S. Department of Energy. The Los Alamos National Laboratory strongly supports academic freedom and a researcher's right to publish; as an institution, however, the Laboratory does not endorse the viewpoint of a publication or guarantee its technical correctness. 


\section{DISCLAIMIER}

This report was prepared as an account of work sponsored by an agency of the United States Government. Neither the United States Government nor any ageacy thereof, nor any of their employees, makes any warranty, express or implied, or assumes any legal liability or responsibility for the accuracy, completeness, or usefulness of any information, apparatus, product, or process disclosed, or represents that its use would not infringe privately owned rights. Reference berein to any specific commercial product, process, or service by trade name, trademark, manufacturer, or otherwise does not necessarily constitute or imply its endorsement, recommendation. of favoring by the United States Government or any agency thereof. The views and opinions of authors expressed herein do not necessarily state or reflect those of the United States Government or any agency thereof. 


\section{DISCLAIMER}

Portions of this document may be illegible in electronic image products. Images are produced from the best available original document. 


\title{
MECHANISMS RESPONSIBLE FOR TEXTURE DEVELOPMENT IN A 5182 ALUMINUM ALLOY DEFORMED AT ELEVATED TEMPERATURE
}

\author{
M.G. Stout ${ }^{\dagger}$, S.R. Chen ${ }^{\dagger}$, U.Fred Kocks ${ }^{\dagger}$, A.J. Schwartz ${ }^{\ddagger}$, S.R. MacEwen ${ }^{\S}$, and A.J. Beaudoin ${ }^{\natural}$ \\ ${ }^{\dagger}$ Los Alamos National Laboratory, Los Alamos, NM 87544, \\ ${ }^{\ddagger}$ Lawrence Livermore National Laboratory, Livermore, CA 94550, \\ ${ }^{\S}$ Alcan International Ltd., Kingston, Ontario, K7L 5L9 CANADA, \\ "University of Illinois at Urbana-Champaign, Department of Mechanical and Industrial \\ Engineering, Urbana, IL 61801
}

\begin{abstract}
The textures that develop in a 5182 aluminum alloy as a result of monotonic high-temperature compression have been investigated. We found that the deformation texture was a function of temperature. For compressive deformation at $300^{\circ} \mathrm{C}$ and below the material formed the classic (101) deformation texture, while the material develops a texture that is a combination of the classical uniaxial compression deformation texture, (101), and static recrystallization texture, (001), as a result of the deformation alone when the deformation temperature was at and above $400^{\circ} \mathrm{C}$. Our investigation has focused on determining the mechanism responsible for the development of this unusual progression of deformation textures.

In order to understand the mechanism(s) responsible for this particular development, we have performed interrupted compression experiments as well as microstructural analyses. The deformation experiments consisted of deforming to a given strain, holding at temperature for various times at zero strain rate, followed by either quenching or further deformation.

In addition we have performed orientation imaging microscopy (OIM) to identify the shapes of grains with particular orientations and grain-to-grain orientation relationships.

Finally, crystal plasticity theory was used to model whether or not deformation via different slip systems and high strain-rate sensitivity could produce the (101) and (001) texture components.

Our conclusions are summarized as follows: The texture development is not a result of static processes, i.e. static recrystallization at the various hold times altered neither the textures nor the constitutive behavior. Simulation using a crystal plasticity model indicates that the combination of a cube component prevalent in the original texture, slip activity on 011 planes, and increased rate sensitivity leads to a combined (001) and (101) texture. Finally, the microscopic OIM results are consistent with these observations.
\end{abstract}




\section{Introduction}

The rolling of aluminum alloys is a most important and widely used industrial process. The materials microstructure, texture, yield strength, and work hardening behavior that result from this process will determine its ultimate formability and engineering properties in applications. Because rolling is such a high volume process and the capital expenditure in plants and fabrication facilities is so high, even small cost savings or increased efficiency can result in a very large total dollar savings. Our aim is to ultimately improve the manufacturing process through numerical simulation. This potentially removes the need for very costly plant trials that are also time consuming to perform.

Accurate descriptions of a materials constitutive behavior are required for good numerical simulations. In addition, it is important that simulations of the rolling process be able to correctly predict the textures that form. Not only will the texture influence the materials formability, but it can affect its constitutive response during deformation as well. A generic example of a rolling process is shown in Figure 1.

Break Down Mill Intermediate Mill · Finishing Stand

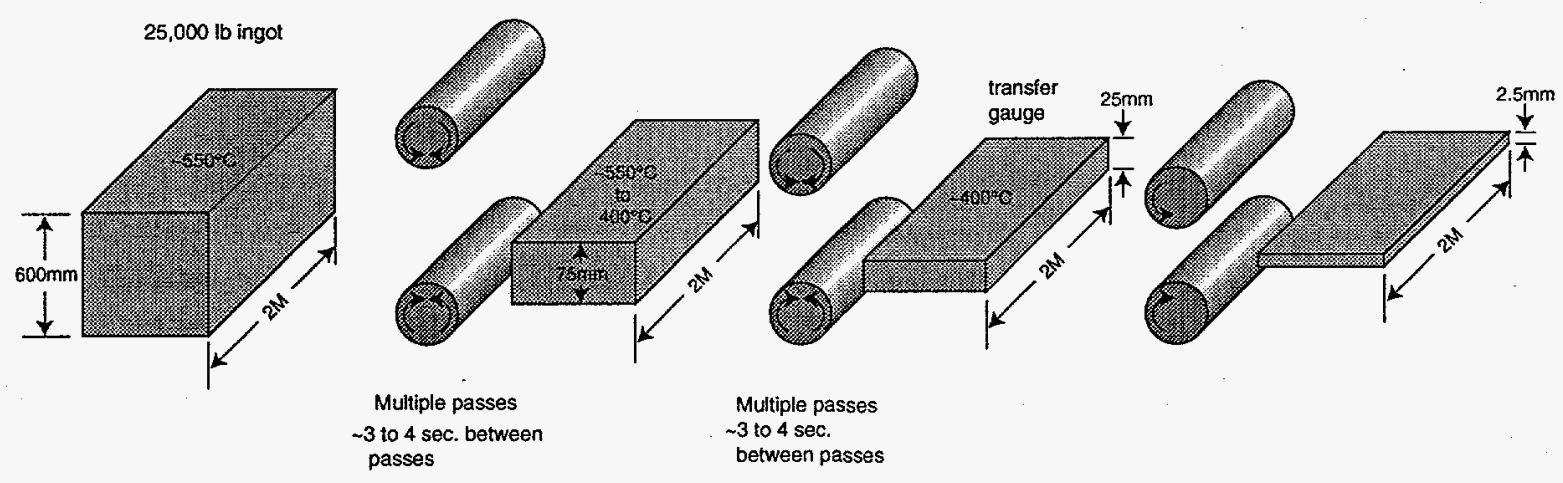

Figure 1: Schematic illustration of a typical rolling process.

Hot rolling is a particularly challenging aspect of the rolling process to simulate because of the wide range of temperatures over which the process occurs. In addition, one expects that the ingot experiences several orders of magnitude difference in strain rates as well. These widely varying conditions represent a particular challenge for modeling.

For our study we selected a 5182 aluminum magnesium manganese alloy. We have begun our investigation by measuring the constitutive response of transfer-gauge material, using compression specimens. These specimens were tested at a number of temperatures between $550^{\circ} \mathrm{C}$ and room temperature, $22^{\circ} \mathrm{C}$, and strain rates of $10^{-3} \mathrm{~s}^{-1}$ and $1 \mathrm{~s}^{-1}$. Our experiments were performed to a true strain of 0.60 . We have measured the textures of the deformed specimens as well their constitutive, stress/strain response. These experiments have formed a basis for the determination of appropriate models of the metals constitutive behavior ${ }^{(1)}$, for understanding the hot deformation processes that are occurring, and for measuring the deformation textures that develop in alloy 5182 at room and elevated temperature. 


\section{Experimental Procedures}

\section{Compression Experiments}

The transfer gauge material that we began with was plate $25.4 \mathrm{~mm}$ thick. Right-cylindrical compression specimens with a $1: 1.33$ aspect ratio, $12.7 \mathrm{~mm}$ in height and $9.5 \mathrm{~mm}$ diameter, were machined from the center of the transfer gauge. Specimens were cut in two orientations: compression axis parallel to the rolling direction, and compression axis aligned with the plate normal direction. A recess, to trap lubricant, was machined into both ends of the specimens in a manner originally used by Rastegaev ${ }^{(2)}$. The recess was $0.25 \mathrm{~mm}$ deep and the ring remaining around the edge of the specimen was $0.5 \mathrm{~mm}$ wide. We used a molybdenum-disulfide lubricant in a grease carrier and thin tungsten-carbide platens in contact with the specimen. The assembly of specimen and tungsten-carbide platens was mounted between two larger steel platens that contained cartridge heaters. Our elevated temperature tests were performed using these heaters and allowing heat to be conducted from the steel platens into the specimen. We were able to attain a temperature gradient of less than $3^{\circ} \mathrm{C}$ in the specimen with this approach. Temperature calibrations with a thermocouple mounted in a test specimen were performed to assure our experiments were at proper temperatures. The tests were performed at temperatures between $22^{\circ} \mathrm{C}$ and $550^{\circ} \mathrm{C}$ and strain rates of $\dot{\varepsilon}=10^{-3} \mathrm{~s}^{-1}$ and $1 \mathrm{~s}^{-1}$. The stress/strain response was calculated from load and crosshead displacement. In these experiments the crosshead displacement was obtained from a single-arm extensometer. We compared these measurements with the final specimen dimension, finding excellent agreement that was devoid of systematic error.

\section{$\underline{\text { Texture Measurements }}$}

We used two techniques to measure the textures of our 5182 aluminum alloy: $x$-ray diffraction and orientation imaging microscopy (OIM). The software package popLA ${ }^{(3)}$ was used to interpret our X-ray data. With this package both pole figures and inverse pole figures can be plotted. A scanning electron microscope is used for the OIM. This is a highly automated technique in which the orientations of individual grains are automatically measured and catalogued from electron back scattered patterns. Image quality is an orientation imaging microscopy parameter which describes the sum of the intensity of the peaks in the Hough transform. It corresponds to the contrast, or quality of the electron back-scatter Kikuchi diffraction pattern. Generally, the quality will be good in the grain interiors, and poorer at the grain boundaries where overlapping patterns may exist. The OIM data can be displayed in many ways. Pole figures can be plotted or a color orientation image of the grains created. In the case of the orientation image, grains of particular orientations have specified colors or gray shades. From such an image one can quickly discern relationships between grains of particular orientations and differences in grain size or shape, depending on orientation. For the orientation imaging micrographs presented in this paper, a gray scale shading scheme is applied. For example, if a grain has a $<101>$ direction within 15 degrees of the plate normal, it is shaded gray. The darker the shade of gray, the more closely aligned the $<101\rangle$ direction is with the plate normal. Grain boundaries are also indicated on these micrographs. A one pixel (thin) line represents a low angle grain boundary with a misorientation between 5 and 15 degrees, whereas a two pixel (thick) line is used to represent grain misorientations greater that 15 degrees

The initial texture of the transfer-gauge material was measured as well as the deformation textures

of the deformed compression specimens. The deformation textures measured by $\mathrm{x}$-ray were taken from a section normal to the compression axis. Each of the compression samples was deformed to 
a true strain of $\approx 0.6$. Thus, the textures are representative of relative large-strain conditions. In the case of the OIM measurements two specimens with different orientations were prepared. We examined the same section as with the x-rays and in addition, looked at a transverse section. That is a section containing the compression axis. In this case one expects the grains to have an oblong shape resulting from the deformation. One should note that our compression specimens were quenched immediately into water following testing. We have mounted a thermocouple in a specimen and then compressed at $400^{\circ} \mathrm{C}$ and a strain rate of $10^{-3} \mathrm{~s}^{-1}$. It took $3 / 4$ of a second from the time the specimen was unloaded until we were able to get it into the quench bath and then another three seconds before the temperature of the specimen was below $300^{\circ} \mathrm{C}$.

\section{Initial Experimental Results}

The starting texture of the transfer gauge was found to be a cube texture of intensity five times random aligned with the axes of rolling orthotropy. Sections were measured at the half, quarter, and eighth planes as well as on the plate surface. Only insignificant differences were observed in the eighth and surface sections. However, textures from the mid plane and quarter sections were identical mild cubes. It is from this region of the plate that all of our specimens were machined.

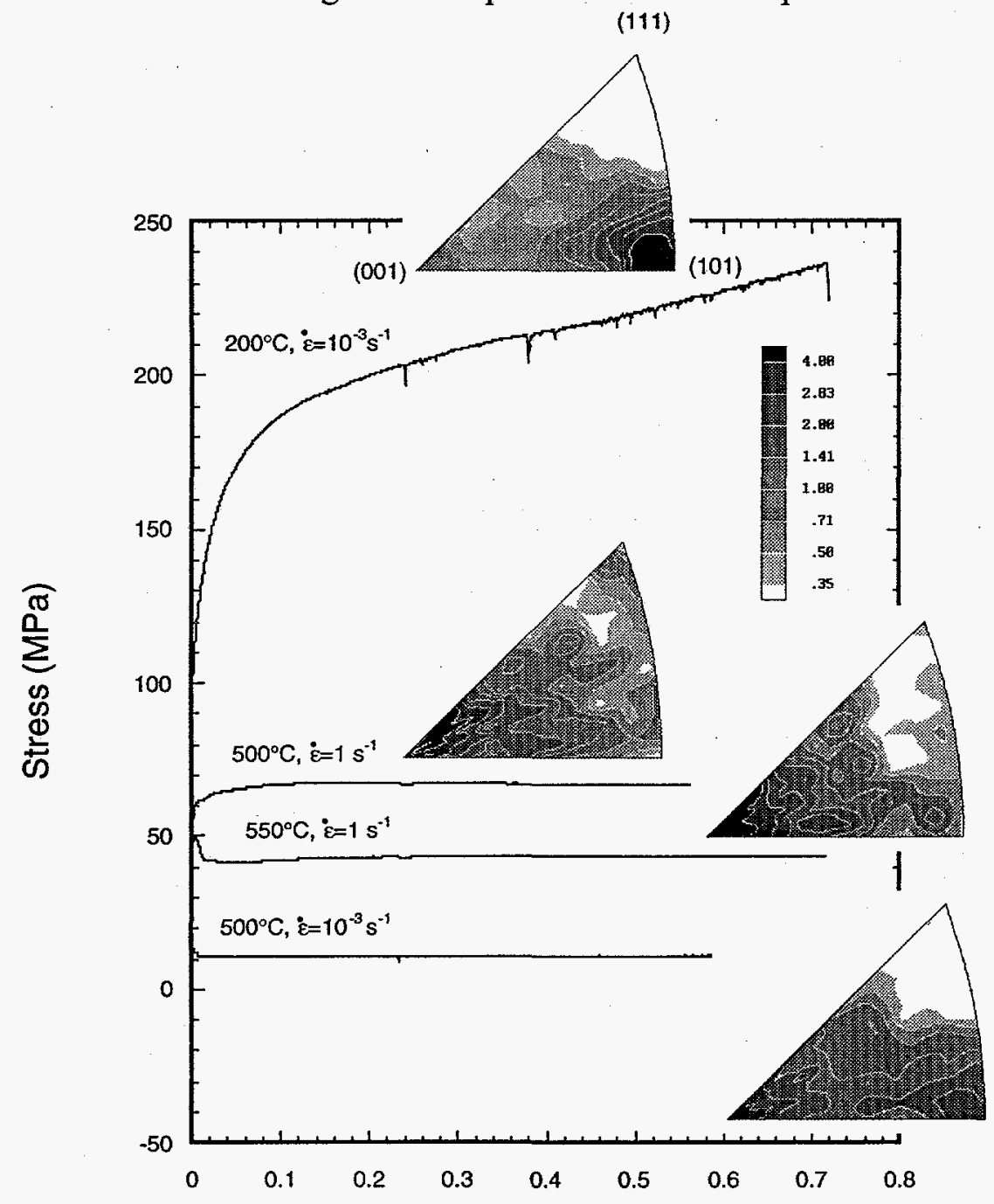

Strain

Figure 2: Stress/strain data for different temperatures and strain rates. The inverse pole figures from these compression specimens are plotted with the respective constitutive data. 
We have summarized representative data from both our stress/strain measurements and texture analysis in Figure 2. One should note that these specimens were all oriented with the compression axis parallel to the rolling direction. Our initial experiments showed no differences between the data from this orientation and that with the compression axis parallel to the plate normal.

The textures are presented, with their corresponding work-hardening curves, as inverse pole figures in Figure 2. In the case of these inverse pole figures the crystal directions parallel to the compression axis are plotted on the standard stereographic triangle.

We found that the 5182 alloy develops a standard compression texture at $200^{\circ} \mathrm{C}$, a (101) fiber texture. The material also has a typical yield and stress/strain response. Nothing appears to be extraordinary. At elevated temperatures, $500^{\circ} \mathrm{C}$ and $550^{\circ} \mathrm{C}$, the behavior is very different. The 5182 has a much lower yield stress and almost no work hardening. When the yield stress was below $50 \mathrm{MPa}$ we observed an upper/lower yield point, with a negative hardening transient. Above $50 \mathrm{MPa}$ there was no yield point; the material hardened normally after yield. The textures that we measured are different from the classical compression deformation texture. For the experiments at $500^{\circ} \mathrm{C}$ and $550^{\circ} \mathrm{C}$ and a strain rate of $1 \mathrm{~s}^{-1}$ the texture had almost no (101) deformation component, rather it is characterized by the (001) cube component. This texture is generally thought of as a recrystallization texture rather than a deformation texture. At $500^{\circ} \mathrm{C}$ and a strain rate of $10^{-3} \mathrm{~s}^{-1}$ we measured both the $(001)$ recrystallization and (101) deformation components. This was also the case for experiments at $550^{\circ} \mathrm{C}$ and $400^{\circ} \mathrm{C}$ and a strain rate of $10^{-3}$ $\mathrm{s}^{-1}$, although these data are not plotted in Figure 2. One should note these specimens had the lowest yield stresses, below $30 \mathrm{MPa}$. Both the texture and stress/strain results are consistent with those of Kocks and Chen ${ }^{(4)}$ for an $\mathrm{Al}-5 \% \mathrm{Mg}$ alloy.

These deformation textures with the recrystallization component pose an interesting question. What is the physical mechanism by which this texture occurs? Is it from static or dynamic recrystallization or is it a result of deformation? The remainder of this paper, experiments and simulations, are an examination of these questions.

\section{Current Experimental Results}

Interrupted Mechanical Tests

Two types of interrupted mechanical tests were performed to investigate if the (001) texture component we observed in hot compression was a result of static recrystallization. The first experiment involves deforming specimens to a strain of 0.6 at $400^{\circ} \mathrm{C}$, unloading, holding at temperature for various times in the unloaded state, and finally quenching. We then measured the textures of each of these specimens. The different hold times at temperature should allow for the recrystallization process to progress through different stages, if static recrystallization were occurring. In the second experiment specimens were loaded, again at $400^{\circ} \mathrm{C}$, to about $50 \%$ strain, unloaded and held for different times at temperature, and finally reloaded. If recrystallization were occurring we would expect that the reloading curve would not rejoin the loading curve. The extent of difference between the loading and reloading curves should also be a function of the hold time.

A thermocouple was mounted in each of the mechanical test specimens intended for texture analysis. The first sample was quenched immediately after unloading. It took $0.75 \mathrm{~s}$ from the time we unloaded the specimen until we could get it into the water quench bath. Once in the bath the 
specimen took another $3 \mathrm{~s}$ to cool from $400^{\circ} \mathrm{C}$ to below $300^{\circ} \mathrm{C}$. Thus, the specimen had roughly 4 $\mathrm{s}$ to statically recrystallize. A second sample was compressed at $400^{\circ} \mathrm{C}$ unloaded and held for $10 \mathrm{~s}$ at temperature, before quenching. Again, it took $3 \mathrm{~s}$ for the specimen to cool below $300^{\circ} \mathrm{C}$ once it was in the water bath. This specimen had approximately three times as long to statically recrystallize as the first. The textures of both specimens were identical and the same as that shown in Figure 2, for the specimen tested at $500^{\circ} \mathrm{C}$ and a strain rate of $10^{-3} \mathrm{~s}^{-1}$. Both the (001) and (101) components are present in these specimens in relatively equal intensity.

In the case of the load/unload/reload experiments the first specimen was immediately reloaded while a second was held at temperature for $5 \mathrm{~min}$. before reloading, to allow for potential static processes to occur. In both experiments the reloading curves rejoined the initial loading response exactly. The only deviation was a slightly higher yield stress followed by an immediate load drop to the loading value of flow stress. The reloading curves, in both experiments, then proceeded with additional deformation as though the interruption never occurred.

\section{OIM Experimental Results}

Some results from our OIM data, for a specimen compressed at $550^{\circ} \mathrm{C}$ and a strain rate of $10^{-3} \mathrm{~s}^{-1}$, are shown below. Figures $3 \mathrm{a}$ and $3 \mathrm{~b}$ are OIM micrographs taken from a transverse section, the section contains the compression axis which has a vertical orientation. In these micrographs grains with a gray scale quality have either a (001) or (101) orientation, Figures $3 \mathrm{a}$ and $3 \mathrm{~b}$ respectively. The orientations shown in these micrographs have been rotated to reflect the orientation one would see viewing down the compression axis, $90^{\circ}$ from the actual sample section orientation. This rotation assures complete consistency between these data and the $\mathrm{x}$-ray inverse pole figures.

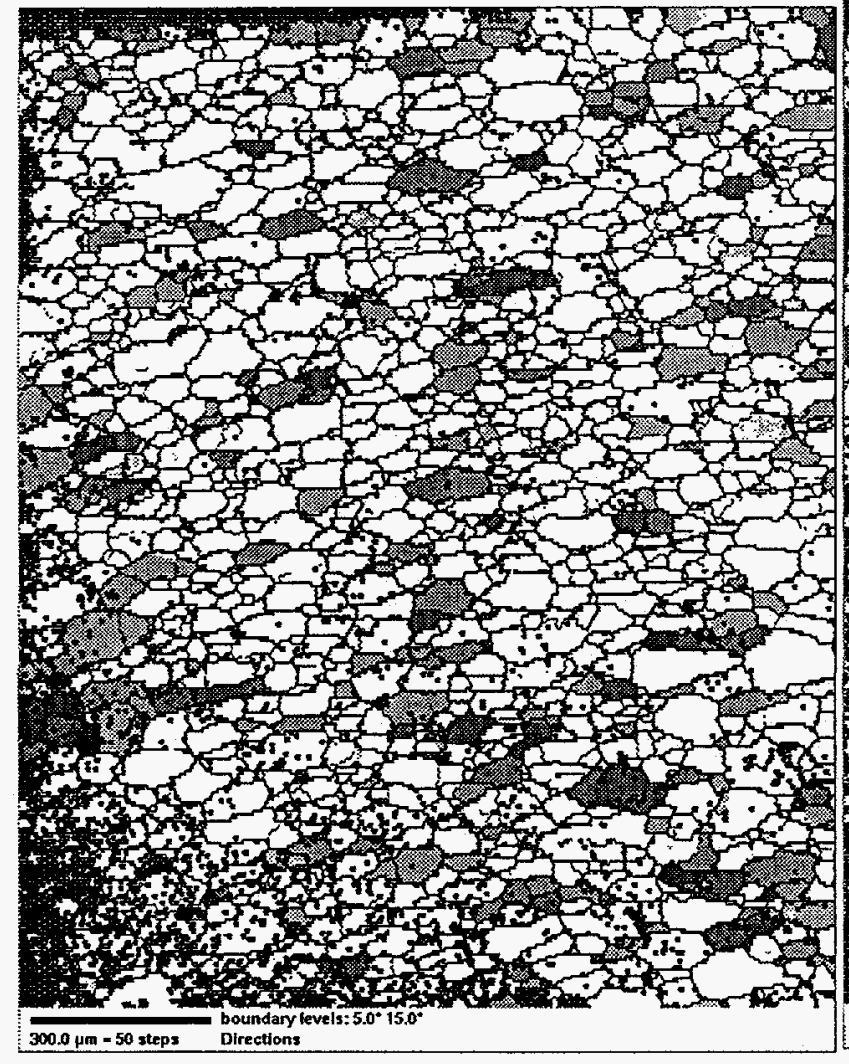

Figure 3a: OIM micrograph showing those grains with a (001) orientation.

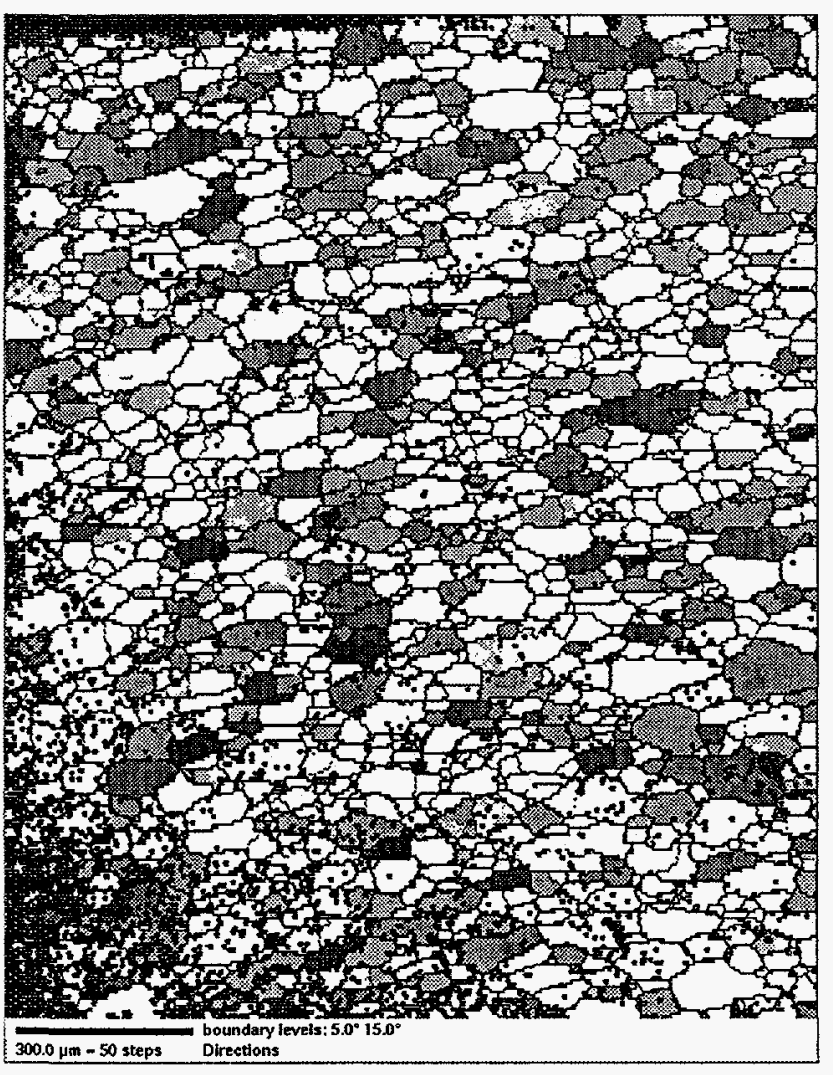

Figure 3b: OIM micrograph showing those grains having a (101) orientation. 
Other small rotations were also made to align the peak intensities of the orientations with the specimens principal axes. This accounts for small angular errors in the mounting and polishing of the specimen.

A visual examination of a single color image containing both orientations, shown above as two separate micrographs, did not show any obvious relationships between the (001) and (101) orientations.

The individual grains of the (001) and (101) orientations, shown in Figures $3 \mathrm{a}$ and $3 \mathrm{~b}$, were measured to determine if grain aspect ratios or overall grain sizes were a function of orientation. One would expect this to be the case if one orientation occurred as a result of deformation while the other was produced by dynamic recrystallization. The dislocation subgrains are polygonized because of the high temperature deformation and thus the internal boundaries are relatively high angle, $>5^{\circ}$. A single grain could possibly contain different regions of gray scale and thin line boundaries between these regions. However, it is often difficult to distinguish if this is the case or if there are individual grains present. To avoid ambiguity, we assumed all boundaries and differences in shading constituted an individual grain. Although some systematic error resulted, the data could be consistently analyzed for both orientations, and we held questions of interpretation to a minimum. In the micrographs shown above we measured 112 grains with the $(001)$ orientation and 324 grains having the (101) orientation. Our measurements were catalogued by the grain aspect ratio and the product of the lengths of the grain's principal axes. In order to quantitatively compare the grain shapes and sizes of the two orientations, normalization by the total numbers of grains and total grain area of each orientation was required. The results of these measurements are shown below in Figures $4 a$ and $4 b$.

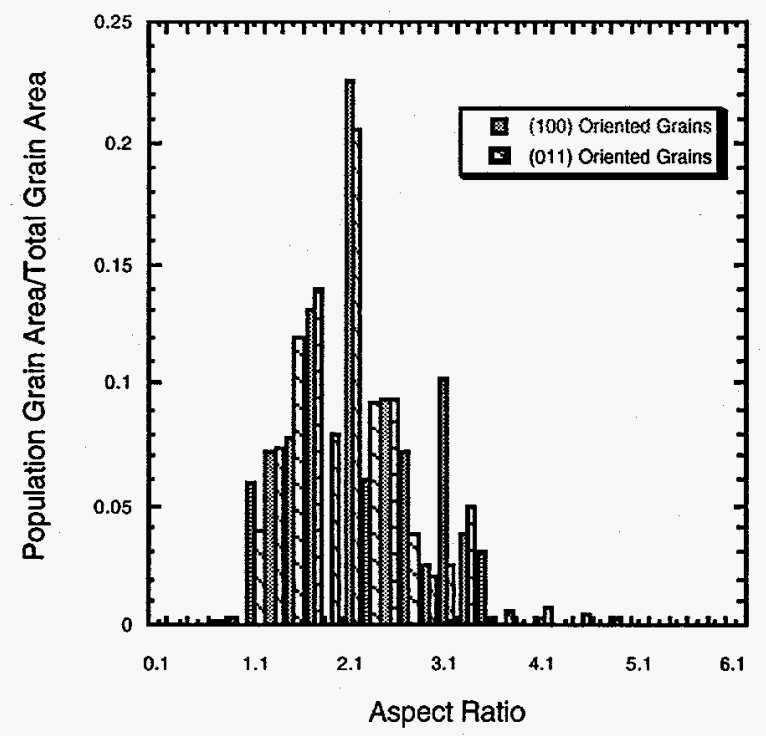

Figure 4a: Histogram showing the normalized areas of the grains as a function of their shape.

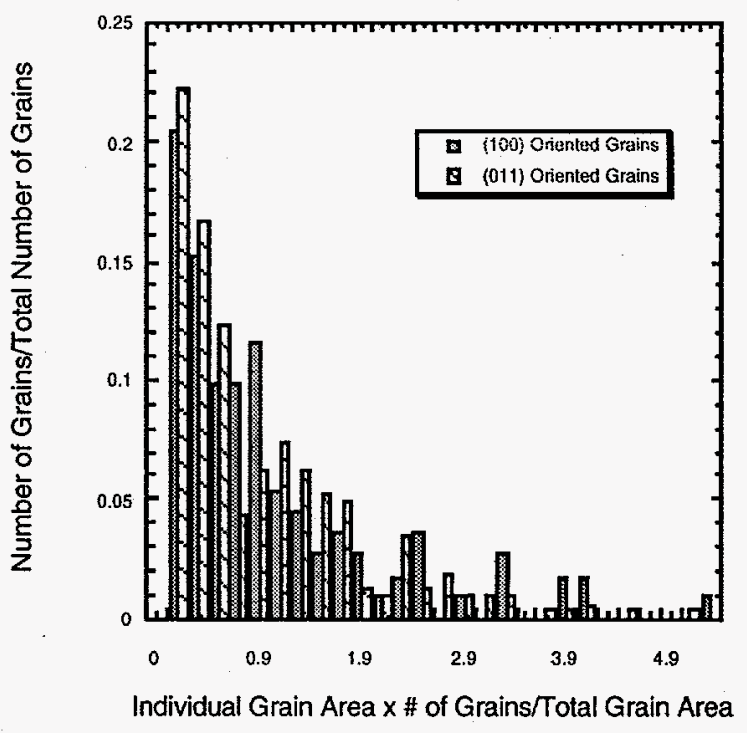

Figure 4b. Histogram showing the number of grains of a given normalized area. 
Based on these measurements we believe that there is no significant difference in the sizes or shapes of the (001) and (101) grains. The trends in the data and even the actual normalized numbers are basically the same. The scatter that we observe is likely attributable to measurement of too few grains and experimental scatter in the actual length measurements, rather than a different physical mechanism being responsible for the formation of the particular orientation.

\section{Polycrystal Plasticity Simulations}

Crystal plasticity theory was used to study formation of the (001) component. Emphasis was placed on identifying the contributions of 1) increased rate sensitivity and 2) slip on the 011 dodecahedral planes (in addition to slip on the usual 111 octahedral planes). Simulations were performed using the LApp (Los Alamos polycrystal plasticity) code. A discretized representation consisting of 768 discrete orientations was created so as to represent the original texture. Using a classical Taylor model, this starting texture was evolved over the course of a uniaxial compression. A strain-rate sensitivity of $1 / 3$ was prescribed and slip systems underwent no hardening - so as to represent the high-temperature, low strain-rate tests in the solute-drag regime.

Results for a simulation with slip admitted solely on the octahedral planes is shown in Figure 5a. Little evidence of the initial (001) component is noticeable. However, it should be noted that the development of the (101) component is retarded in comparison to simulations which adopt a near rate-independent response. Addition of the dodecahedral planes leads to a combined texture, consisting of the cube and (101) texture components (Figure 5b). To establish the origin of this cube component, the numerical procedure was repeated with an initially random texture. In this case, a cube component with similar intensity did not develop. It is the cube component present in the initial texture that is retained during deformation.

The numerical studies suggest that a combination of three factors leads to the development of the combined (001) and (101) texture. The cube component is prevalent in the original texture, providing a source of cube to be carried through the deformation. The increased rate sensitivity serves to slow evolution of the texture, specifically development of the familiar(101) component associated with compression of fcc metals. Slip activity on 011 planes also serves to retain the cube component. It has not been definitively established so far whether this is a true stability or merely another decrease in the rate of texture evolution away from the (001).

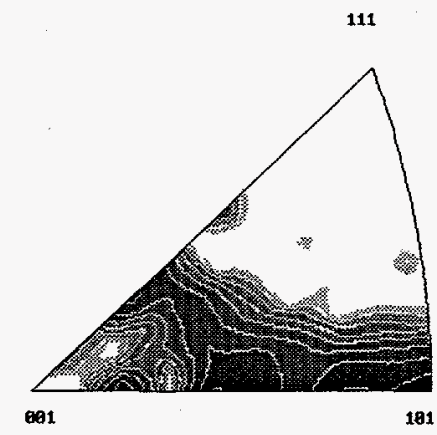

Figure 5a: The compression deformation texture calculated assuming only octahedral slip planes. Contours are as in Figure 2.

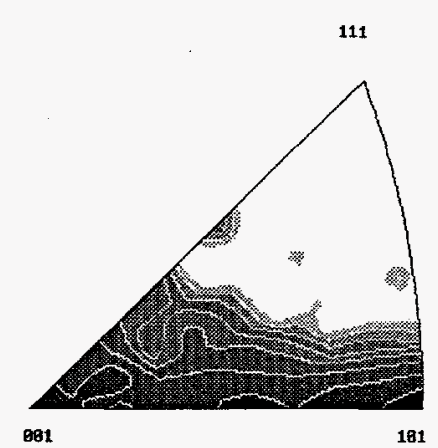

Figure 5b: Crystal plasticity calculation based on both (111) and (101) slip planes. Contours are as in Figure 2. 


\section{Discussion}

Chen et.al. ${ }^{(1)}$ have shown that the constitutive behavior of the 5182 alloy falls into three regimes. At and slightly above room temperature, $22^{\circ} \mathrm{C}$, deformation is characterized by dynamic strain aging ${ }^{(5,6)}$. Thermally-activated dynamic recovery ${ }^{(7)}$ dominates the deformation mechanism at moderate temperatures while diffusion controlled solute drag ${ }^{(8)}$ governs at high temperatures. The very high strain-rate sensitivity, $\mathrm{m} \approx 0.3$, is characteristic of the solute drag deformation regime.

Chen et.al. (1) have shown that one can model the yield behavior of 5182 aluminum in the solute drag regime using a Dorn type relationship:

$$
\dot{\varepsilon}=A\left(\frac{\sigma}{\mu}\right)^{3} \frac{\mu b^{3}}{k T} \exp \left(-\frac{Q_{D}}{k T}\right)
$$

Where, $Q_{D}$ is taken to be the activation energy for self diffusion of the diffusing species. In this case we have used the value for Al-Mg, which is $131 \mathrm{~kJ} / \mathrm{mol}$. Allowing the exponent to deviate slightly from 3 Chen et.al. made the following plot of yield stress as a function of logarithm strain rate for their high temperature constitutive data; see Figure 6. The data which fall on the line with the slope of 2.74 are characterized by the solute drag mechanism and very high strain-rate sensitivity. At lower temperatures and higher strain rates the solute-drag mechanism gives way to classical thermally-activated dynamic recovery. A line through these data would still have a positive slope but much shallower. The transition in our data between these two mechanisms is sharp and occurs at two particular test conditions, $300^{\circ} \mathrm{C}-\dot{\varepsilon}=10^{-3} \mathrm{~s}^{-1}$ and $500^{\circ} \mathrm{C}-\dot{\varepsilon}=1 \mathrm{~s}^{-1}$.

We have superimposed inverse pole figures of our measured textures for particular temperature and strain rate conditions shown on the plot. One can see that with the exception of the inverse pole figure from the specimen tested at $500^{\circ} \mathrm{C}$ and a strain rate of $\dot{\varepsilon}=10^{-3} \mathrm{~s}^{-1}$, the textures evolve progressively from bottom to top. At the higher temperatures and lower strain rates the specimens had the two component (001) cube and (101) textures. In the strain rate/temperature regime characterized by thermally activated recovery the texture of all of the specimens was dominated by the (101) compression deformation texture. This was the case for all conditions, including those for which an inverse pole figure is not plotted. As we have noted, an exception to this is the specimen tested at $500^{\circ} \mathrm{C}$ and higher rate (although not shown $550^{\circ} \mathrm{C}-\dot{\varepsilon}=1 \mathrm{~s}^{-1}$ as well). These two specimens had textures with only a (001) cube component superimposed over a "noisy" fairly random background.

Our OIM data does not substantiate the process of dynamic recrystallization producing the (001) texture component. If the $(001)$ oriented grains are forming as a result of recrystallization we would expect the grains to be nearly equiaxed and skewed towards a small size distribution. This was not the case. The (001) grains had the same aspect ratio distribution as those with a deformation orientation, (101). The distortions of these grains from an equiaxed shape was consistent with the total amount of deformation that was imposed on the compression specimens. In addition to shape, the grain size distributions also do not fit a pattern we would expect from recrystallization. We observed that both the (001) and (101) oriented grains had the same normalized area distributions. The fractions of numbers of grains of a given area were the same independent of orientation. These observations indicate that the (001) grain orientation has not 
formed principally as a result of dynamic recrystallization. Other published results report a negligible amount of dynamic recrystallization occurring for these deformation conditions ${ }^{(9-11)}$.

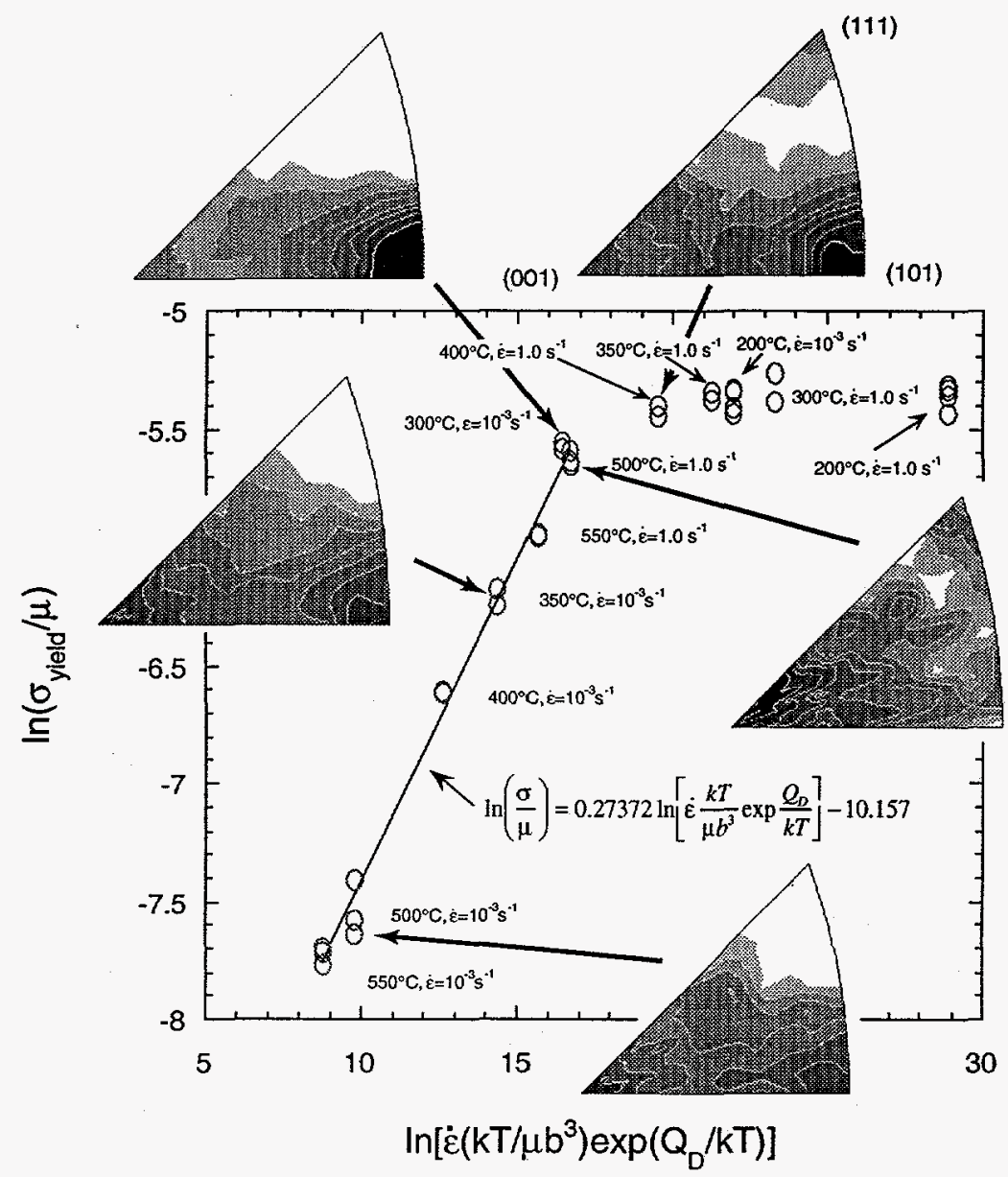

Figure 6: A plot showing the strain-rate sensitivity of the 5182 as a function of strain rate and temperature. One can see that the (001) cube texture exists for those conditions of both high temperature and very high rate sensitivity. Contours are as in Figure 2.

From our interrupted mechanical-deformationexperiments it does not appear as though the two component texture is forming as a result of partial static recrystallization. If the recrystallization were complete we would not expect to see any of the (101) component and if there was partial static recrystallization we would have expected to see the components evolve as a function of quench time. This did not occur. Our load/unload/reload experiments also suggest that static recrystallization is not occurring. If static recrystallization were taking place the reloading curves should not have rejoined the loading curve as they did. The possible exception to these conclusions are the specimens which were tested at $550^{\circ} \mathrm{C}$ and $500^{\circ} \mathrm{C}-\dot{\varepsilon}=1 \mathrm{~s}^{-1}$. Both of these testing conditions produced a $(001)$ texture without the deformation component. This could be the result of static recrystallization. Both the yield stress and temperature are high for these conditions, perhaps high enough to provide sufficient energy for recrystallization. In addition, we know that the quench rate for these specimens is insufficient to preclude static recrystallization. It took $3 \mathrm{~s}$ for the water quench to drop the temperature of the $400^{\circ} \mathrm{C}$ specimen to $300^{\circ} \mathrm{C}$. This time would have been even longer for the specimens at $500^{\circ} \mathrm{C}$ and $550^{\circ} \mathrm{C}$. Optical metallography needs to be performed on these samples to determine if recrystallization has in fact occurred. 
Maurice and Driver ${ }^{(12,13)}$ have observed slip on the (101) planes in Al-1\%Mn single crystals at and above $350^{\circ} \mathrm{C}$. Their conclusion was based on slip-line observations from single crystals tested by channel-die compression. They found that the (101) slip was accompanied by the classical (111) slip and that the (101) slip systems stabilized an initial cube orientation in a polycrystal. They modeled these experimental observations successfully using the Lebensohn and Tomé selfconsistent crystal-plasticity theory ${ }^{(14)}$.

Our Taylor calculations also predicted the stabilization of the (001) texture component initially present in the material. We found that to retain some of the (001) component required two conditions in the simulation, (101) slip and a high strain-rate sensitivity associated with the single crystal flow law. Our experimental texture results are fully consistent with the model predictions and Maurice and Driver's experimental results. All of our texture measurements, from specimens tested at and below $300^{\circ} \mathrm{C}$, did not show the (001) cube component. This was the case (see Figure 6 ) even if the strain-rate sensitivity was very high. The specimen compressed at $300^{\circ}$ and a strain rate of $10^{-3} \mathrm{~s}^{-1}$ had a pure deformation texture, very little (001) component. However, this same condition is characterized by a very high strain-rate sensitivity; the specimen is deforming by the solute-drag mechanism. Based on Maurice and Driver's work we would expect the (101) slip to be active at $400^{\circ} \mathrm{C}$. Indeed, at $400^{\circ} \mathrm{C}$ and a strain rate of $10^{-3} \mathrm{~s}^{-1}$ the (001) cube texture component is present. However, when we tested at $400^{\circ} \mathrm{C}$, but a strain rate of $\dot{\varepsilon}=1 \mathrm{~s}^{-1}$, the (001) cube component is greatly diminished; see Figure 6 . At this combination of temperature and strain rate deformation is characterized by a thermally-activated recovery mechanism, and the strain-rate sensitivity is low. Despite the fact that (101) slip should be active the (001) cube component was not stable.

\section{Summary}

We have tested 5182 aluminum alloy in compression at a variety of temperatures and strain rates. The textures that formed in these compression specimens were evaluated, and particular trends emerged. At lower temperatures and higher strain rates a classical (101) compression deformation texture occurred. At high temperatures and low strain rates a two component, (001) cube and (101) compression deformation, texture was measured. There were two exceptions to these observations, specimens tested at $550^{\circ} \mathrm{C}$ and $500^{\circ} \mathrm{C}-\dot{\varepsilon}=1 \mathrm{~s}^{-1}$. We attribute the texture of these specimens to static recrystallization, although work remains to be done to verify this.

Based on crystal-plasticity simulations starting with a representation of our materials initial texture, we found that we do not need to invoke recrystallization, either static or dynamic, to retain some of the (100) cube component. The cube component, which is initially present in our compression specimens, remains if we allow (101) slip to occur and use the high value of strainrate sensitivity characteristic of this alloy when deformation is at high temperature and low strain rate. The temperatures where we believe that the texture indicates the presence of (101) slip are consistent with the work of Maurice and Driver ${ }^{(12,13)}$. Both (101) slip and the high strain-rate sensitivity were important parts of our simulation. Their mutual importance was consistent with our texture measurements.

\section{Acknowledgments}

The researchers at Los Alamos National Laboratory and Lawrence Livermore National Laboratory gratefully acknowledge the financial support of Basic Energy Sciences, Division of Materials Sciences, US Department of Energy. 


\section{REFERENCES}

1. S.R. Chen, M.G. Stout, U.F. Kocks, S.R. MacEwen, and A.J. Beaudoin "Constitutive Modeling of a 5182 Aluminum Alloy as a Function of Strain Rate and Temperature," in Hot Deformation of Aluminum Alloys II, eds. T.R. Bieler, L. Lalli, and S.R. MacEwen, (Warrendale, PA: TMS The Minerals Metals Minerals Society, 1998), in press.

2. M.V. Rastegaev, "A New Method of Homogeneous Compression of Specimens for Determining Flow Stress and the Coefficient of Internal Friction," ZADOVSK LAB., 6, (1940), p. 345.

3. U.F. Kocks, C.N. Tomé, H.-R. Wenk, Texture and Anisotropy, (Cambridge University Press, 1998) in press.

4. U.F. Kocks, and S.R. Chen, "Constitutive Laws for Deformation and Dynamic Recrystallization in Cubic Metals," in Proceedings of the $7^{\text {th }}$ JIM International Symposium (JIMIS-7) on Aspects of High Temperature Deformation and Fracture in Crystalline Materials, eds. Y Hosoi, H. Yoshinaga, H. Oikawa and k. Maruyama, (The Japanese Institute of Metals, 1994), 593-600.

5. S. R. MacEwen, and B. Ramaswami, "Dynamic Strain Aging and Jerky Flow in Al-Mg Single Crystals," Phil. Mag., 22, (1970), 1025-1037.

6. D. J. Lloyd, and D. Kenny, "The Large Strain Deformation of Some Aluminum Alloys," Metall. Trans. A, 13A, (1982), 1445-1452.

7. R. A. Ayres, "Alloying Aluminum with Magnesium for Ductility at Warm Temperatures (25 to 250ㄷ)," Metall. Trans. A., 10A, (1979), 849-854.

8. G. A. Henshall, M. E. Kassner, and H. J. McQueen, "Dynamic Restoration Mechanisms in Al5.8 At. Pct Mg Deformed to Large Strains in the Solute Drag Regime," Metall. Trans. A, 23A, (1992), 881-889.

9. C. Maurice, and J. H. Driver, "High Temperature Plane Strain Compression of Cube Oriented Aluminum Crystals," Acta Metall. Mater., 41, (1993), 1653-1664.

10. C. Maurice, M.-C. Theyssier, and J. H. Driver, "Which Slip Systems in Hot-Rolled Aluminum?," in Advances in Hot Deformation Textures and Microstructures, ed. J. J. Jonas, T. R. Bieler and K. Bowman (Warrendale: TMS, 1994), 411-425.

11. H. J. McQueen, "Initiating Nucleation of Dynamic Recrystallization, Primarily in Polycrystals," Mater. Sci. Engr., 101, (1988), 149-160.

12. Cl. Maurice and J.H. Driver, "Hot Rolling Textures of f.c.c. Metals-Part I. Experimental Results on Al Single and Polycrystals," Acta mater., 45, (1997), 4627-4638.

13. Cl. Maurice and J.H. Driver, "Hot Rolling Textures of f.c.c. Metals-Part II. Numerical Simulations," Acta mater., 45, (1997), 4639-4649.

14. R.A. Lebensohn and C. N. Tomé, "A Self Consistent Anisotropic approach for the Simulation of plastic Deformation and Texture Development in Polycrystals - Application to Zirconium Alloys," Acta Metall. Mater., 41, (1993), 2611-2624. 